WNGE
LANEA

\section{EI viaje}

de Sergio Pitol

\section{Luz Fernández de Alba}

\section{El libro es un diario}

en el que Pitol no solo

hace una crónica de

los sitios visitados, sino que enriquece el relato con las múltiples referencias culturales que convierten el recorrido en un viaje.

E ste libro de viajes se inicia con una espléndida introducción en la que el autor trata de explicarse por qué no ha escrito ningún texto sobre Praga, esa prodigiosa ciudad cargada de referencias literarias en la que él vivió como embajador de México de 1983 a 1988, un periodo determinante en la historia del mundo. Con su estilo oblicuo, Pitol se aproxima durante 15 páginas a la Praga medieval, cuyas calles torcidas recorrió por cinco años al barrio judío, a los cafés frecuentados por Kafka y otros intelectuales, a la Praga mágica de Ripellino, a la ciudad nueva, a la atmósfera enrarecida y tensa que propiciaban los soviéticos desde la primavera de 1968. Sin escatimar ningún detalle que pudiera interesar al viajero, Pitol conduce al lector por la ciudad en un viaje del que ninguna guía o enciclopedia podrían dar cuenta. Concluye la introducción afirmando que al no encontrar en sus diarios algo importante qué decir de Praga, en esta ocasión no escribirá sobre esa ciudad pero que lo hará, en cambio, del "país de las grandes realizaciones y los horribles sobresaltos": la Unión Soviética.

El viaje relata el periplo de dos semanas que realizó el escritor en 1986 por algunas ciudades soviéticas. Sergio Pitol había estado ya cuatro años como embajador de México en Checoslovaquia cuando recibió una invitación de la Unión de Escritores de Georgia para pasar unos días del mes de mayo en Tbilisi, la capital de la República de Georgia, y sus alrededores, con la aclaración de que se le invitaba en su calidad de escritor y no como miembro del Servicio Exterior mexicano. Unos días más tarde, la Asociación de Escritores Soviéticos lo invitaba a dar una conferencia en Moscú. El escritor, no el diplomático, aceptó las dos invitaciones pensando en ir primero a Moscú para de ahí partir a Georgia. Dicha República Soviética era el verdadero interés de su viaje porque ahí se estaban produciendo una literatura y un cine mucho más libres que en el resto de la URSs. Adicionalmente, los georgianos tenían fama de ser un pueblo abierto, alegre, hermoso y poco apegado a la burocracia soviética.

Como siempre hacía antes de emprender un viaje, buscó todas las referencias literarias que tenía de la Georgia actual. Así nos informa que fue en otro tiempo la Cólquide famosa, la patria de Medea, el lugar hasta donde llegó Jasón con los argonautas para apoderarse del Vellocino de Oro.
Datos que no hicieron más que aumentar su deseo de conocerla. Sin embargo, su primer destino tenía que ser Moscú, porque así era el orden de las fechas para las cuales había sido invitado. Volando directamente de Praga a Moscú, llegó a esta ciudad el 19 de mayo de 1986, fecha en que se inicia el anunciado viaje.

El libro es un diario en el que Pitol no solo hace una crónica de los sitios visitados, sino que enriquece el relato con las múltiples referencias culturales que convierten el recorrido en un viaje a través de la literatura rusa. Igualmente reproduce para sus lectores la atmósfera política, social y cultural que encontró en Moscú, donde él había vivido un largo periodo varios años atrás, cuando fue Consejero Cultural en la Embajada de México.

En 1986, la vida soviética estaba entintada por la perestroika y la glasnost que, como es natural, tenían sus adeptos y sus enemigos. Ambos igualmente convencidos, aunque unos ocultos y otros abiertos. Todos hablaban con cautela y los dirigentes de la Asociación de Escritores de la URSS parecían estar empeñados en que el escritor mexicano no visitara la ciudad de Tbilisi.

"En cuanto a su estructura -declaró Pitol en una entrevista en el periódico La Crónica-, El viaje es quizá lo más radical que he hecho". Efectivamente, comienza con la crónica de cada día, las personas a las que conoció, los recuerdos que le suscitó la ciudad, los amigos que reencontró, los restaurantes, las comidas, su identificación con el alma rusa, fragmentos de conversaciones, los libros que leía durante el viaje, lo que soñaba, citas de autores rusos, las representaciones teatrales a las que asistía, sus preferencias literarias, descripciones de la arquitectura anterior a la soviética y sus obser- 
vaciones, siempre eruditas e informadas, de lo que estaba viviendo durante el viaje.

Pero las interesantes crónicas de sus días de viaje por Moscú, Leningrado y, finalmente, Tbilisi, se interrumpen en varias ocasiones para dar paso a diferentes textos que, intercalados, completan la visión del viajero: una carta estremecedora del director teatral Méyerhold, encontrada en los archivos literarios de la KGB, en la que se concentra el terror de las grandes purgas de la época estalinista; un prolijo retrato de la aristócrata rusa Marina Tsvietáieva, brillante poeta y escritora que se suicidó en 1941; una página de $\mathrm{La}$ verdadera vida de Sebastian Knight, de Nabokov; y un delicioso cuento propio, muy breve, titulado "Iván, niño ruso".

Como en el viaje clásico, el escritor debe sortear los obstáculos que se interponen en su camino para impedirle llegar a su meta: la ciudad de Tbilisi. En este caso, una maraña de trabas y misterios burocráticos y políticos, reflejo de las tensas relaciones políticas entre Moscú y Georgia. Cuando Pitol está a punto de renunciar al prometido viaje y regresar a Praga, misteriosamente se aclara todo y, finalmente, diez días después de su llegada a la URss, lo encontramos en Tbilisi.

El escritor vislumbra la ciudad a la luz de la luna y la encuentra espectacular, diferente a todas las ciudades soviéticas que ha conocido. Al día siguiente, con el sol de primavera, descubre la magnificencia de las montañas y la arquitectura que la hacen parecer como una ciudad andaluza enclavada en el Cáucaso. El nivel de vida, lo nota de inmediato, es superior al de Moscú y Leningrado.

Son cinco días los que permanecerá en la deseada capital georgiana, cinco días rigurosamente relatados con una combinación de
Los tesoros artísticos que va descubriendo, las manzanas y las peras gigantes, el vino rojo oscuro, los banquetes pantagruélicos, la sensualidad que se respira en el ambiente, hacen lamentar al escritor no encontrar palabras suficientes para describir sus experiencias, $y$, a nosotros los lectores, no haber estado.

humor, erudición, ligereza y precisión, que nos estimulan a conocer más de esa prodigiosa ciudad. Junto con el escritor realizamos un intenso recorrido de aprendizaje a través de las varias capas culturales que se han sobrepuesto en la región y de los autores rusos o georgianos que le han cantado al Cáucaso. Los tesoros artísticos que va descubriendo, las manzanas y las peras gigantes, el vino rojo oscuro, los banquetes pantagruélicos, la sensualidad que se respira en el ambiente, hacen lamentar al escritor no encontrar palabras suficientes para describir sus experiencias, $y$, a nosotros los lectores, no haber estado nunca en Georgia.

El escritor viaja completamente alerta para no dejar escapar ningún detalle que más tarde pudiera usar en su literatura. Ya en la crónica de su segundo día en Moscú relata que entre el escaso público que asistió a su conferencia sobre la primera novela mexicana, en la biblioteca de Lenguas
Extranjeras, se encontraba en primera fila la viuda del famoso antropólogo armenio Karapetián, quien había estudiado algunos ritos indígenas en México. Más tarde, ya en Georgia y por medio del torbellino de sensaciones, recuerdos y reflexiones que el viaje le despierta, el escritor concibe una nueva novela. Febrilmente toma apuntes, bosqueja personajes, imagina situaciones y se propone iniciar la escritura en cuanto regrese a Praga. La señora Karapetián, que viera tan solo durante su conferencia en Moscú, se transformará en Marietta Karapetiz y será la protagonista. Lo que en El viaje leemos como un embrión, se convirtió en su cuarta novela, Domar a la divina garza, efectivamente terminada en Praga en 1988, tan solo dos años después de haberla imaginado en la URss.

Durante todo este viaje memorable, que llega a su fin con una gran fiesta en el restaurante más sofisticado que existía en el Moscú de 1986, el escritor ha tomado la distancia necesaria para ver su situación personal dentro de ese viaje organizado especialmente para él, como la vería un observador externo. Es como si el narrador tuviera una cámara fotográfica con la que registrara todo el panorama, cuyos detalles solo se harán notables al viajero a su regreso y ya en la calma de su hogar. El lector, que ha acompañado a Pitol en su periplo soviético, ha aprendido mucho acerca de las ciudades visitadas, de los paisajes que las rodean y de lo que puede encontrar en ellas pero, sobre todo, ha aprendido mucho del alma rusa y de la existencia de esos "otros" que, por comodidad, llamamos simplemente rusos. LPyH

Luz Fernández de Alba es maestra en Letras Iberoamericanas por la UNAM y profesora en la misma institución. Autora de Sergio Pitol, ensayista (Uv). 